\title{
Frequency of meal and snack consumption and nutrient intake in schoolchildren in Scotland: term-time $v$. holidays and weekdays v. weekends
}

\author{
J. E. Cameron ${ }^{1}$, J. I. Macdiarmid ${ }^{2}$, L. C. A. Craig ${ }^{1,2}$, G. McNeill ${ }^{1,2}$, L. F. Masson ${ }^{1}$ and C. Sheehy ${ }^{3}$ \\ ${ }^{1}$ School of Medicine, University of Aberdeen, Aberdeen, UK, ${ }^{2}$ Public Health Nutrition Research Group, Rowett Research \\ Institute, Aberdeen, UK and ${ }^{3}$ Scottish Centre for Social Research, Edinburgh, UK
}

Increasing levels of childhood obesity have raised concerns about the eating habits of children. The aim of the present study was to investigate meal and snack patterns and nutrient intakes of Scottish schoolchildren comparing term-time $v$. holidays and weekday $v$. weekends during term-time.

As part of a national cross-sectional dietary survey of Scottish children conducted in 2006, a subsample of children aged 5-17 years completed a $4 \mathrm{~d}$ non-weighed-diet diary ( $n$ 156; eighty-one boys and seventy-five girls). These diaries were analysed to describe the frequency of meal and snack consumption per d and average daily nutrient intakes. Eating events were defined as meals or snacks, with each eating event being separated by a minimum of 30 min. The definition of meals and snacks was adapted from Kelly et al. ${ }^{(1)}$ in which foods were coded into 'core' and 'non-core' foods. Meals were defined as an eating event containing one or more 'core' foods, while a snack contained no 'core' foods. The average number of meals and snacks eaten per $\mathrm{d}$ and the average daily nutrient intakes were compared between subgroups defined by age (5-11 years and 12-17 years), gender, term-time or holidays and weekdays or weekends. Comparison of term-time and holiday included intakes from only weekdays (excluding the weekend) and excluded children whose diary spanned term-time and holiday. The within-subject analysis comparing week and weekend days was based on diaries only completed during term-time ( $n$ 106).

The median) number of eating events per child for the whole sample ( $n$ 156) was 5.3 (interquartile range (IQR) 4.8-6.0) per d, and comprised 3.3 (IQR 2.8-3.5) meals plus 2.0 (IQR 1.5-2.8) snacks. There were no significant differences in the number of meals and snacks eaten between age-groups or between term-time $v$. holiday subgroups. A significantly higher number of meals were eaten per d by boys (3.3 (IQR 3.0-3.5)) than by girls (3.0 (IQR 2.8-3.5); $P=0.032)$ in the whole sample. A significantly higher number of meals were eaten on weekdays (3.0 (IQR 3.0-3.7)) than weekends (3.0 (IQR 3.0-3.0); $P=0.015$ ) and this pattern remained when data from term-time and holiday were combined. The Tables show the mean and $95 \%$ confidence interval (CI) of average daily nutrient intakes for term-time $v$. holidays and weekdays $v$. weekends (term-time only). There were no significant differences in the average daily nutrient intakes between these groups $(P<0.05)$.

\begin{tabular}{lcccccc}
\hline & \multicolumn{4}{c}{ Average daily nutrient intake } \\
\cline { 2 - 3 } \cline { 5 - 7 } & \multicolumn{2}{c}{ Term-time $(n$ 114) } & & \multicolumn{3}{c}{ Holidays $(n$ 34) } \\
\cline { 2 - 3 } \cline { 5 - 7 } & Mean & $95 \%$ CI & & Mean & 95\% CI & $* P$ \\
\hline Energy (kJ) & 7061 & $6747-7374$ & & 7050 & $6107-7994$ & 0.807 \\
Non-milk extrinsic sugars (\% food energy) & 15.7 & $14.6-16.9$ & & 14.3 & $11.6-17.0$ & 0.334 \\
Total fat (\% food energy) & 33.4 & $32.4-34.3$ & & 34.4 & $32.6-36.1$ & 0.401 \\
SFA (\% food energy) & 14.2 & $13.7-14.8$ & & 14.5 & $13.6-15.5$ & 0.604 \\
\hline
\end{tabular}

* Adjusted for age, sex and SIMD

\begin{tabular}{|c|c|c|c|c|c|}
\hline & \multicolumn{5}{|c|}{ Average daily nutrient intake in term-time } \\
\hline & \multicolumn{2}{|c|}{ Weekdays (n 106) } & \multicolumn{3}{|c|}{ Weekends $(n$ 106) } \\
\hline & Mean & $95 \% \mathrm{CI}$ & Mean & $95 \% \mathrm{CI}$ & $P$ \\
\hline Energy $(\mathrm{kJ})$ & 7014 & $6681-7346$ & 6775 & $6400-7150$ & 0.167 \\
\hline $\begin{array}{l}\text { Non-milk extrinsic sugars } \\
\text { (\% food energy) }\end{array}$ & 15.9 & $14.7-17.1$ & 16.3 & $14.5-18.1$ & 0.634 \\
\hline Total fat ( $\%$ food energy) & 33.1 & $32.2-34.1$ & 32.8 & $31.4-34.3$ & 0.697 \\
\hline SFA ( $\%$ food energy) & 14.2 & $13.6-14.7$ & 13.6 & $12.9-14.3$ & 0.182 \\
\hline
\end{tabular}

Nutrient intake or frequency of meal and snack consumption among children in Scotland in the present study did not differ between term-time and holidays. Children tended to consume more meals on weekdays compared with weekends, but there was no difference in their average daily nutrient intake between these days.

This study was funded by the Food Standards Agency (Scotland).

1. Kelly B, King L, Bauman A, Smith BJ \& Flood V (2007) Aust NZ J Public Health 31, 340-343. 